\title{
Did Federal Regulation Discourage Facilities-Based Entry into U.S. Local Telecommunications Markets?
}

\author{
Troy Quast* \\ Sam Houston State University \\ tcq001[at]shsu.edu \\ 2007-06
}

\begin{abstract}
In the United States from 2001 to 2006, federal regulations allowed entrants to lease from incumbents at relatively low cost all of the network infrastructure necessary to provide local phone service. These platform entrants could then provide phone service without installing any of their own equipment. Advocates of this policy claimed that it was needed to provide an economically feasible means by which entrants could serve residential customers. Critics contended that the policy substantially deterred loop entry whereby entrants installed their own switching equipment and leased only the wires that connect a customer's premises to the telephone network. An analysis of panel data for each state over this period indicates that the policy's critics may have been correct. The crossprice elasticity of loop entry with respect to platform price was roughly 1.0. A back of the envelope calculation suggests that loop entry may have decreased by roughly $20 \%$ due to platform entry price reductions.
\end{abstract}

*I thank Donald Stockdale and Ellen Burton of the FCC for their insights into the FCC data. This paper also benefitted from comments by participants at the 2007 International Industrial Organization Conference. Finally, I am indebted to Chunrong Ai, David Gabel, Mark Jamison, and especially David Sappington for their valuable advice. 


\section{Introduction}

One of the largest disappointments of the landmark Telecommunications Act of 1996 (TA96)[13] is the lack of competitive entry into local telecommunications markets. On the day the bill was signed, the CEO of AT\&T, Robert Allen, pledged that his company alone would capture one-third of the local telephone market within five years. [1] However, nine years after the law took effect, the combined market share of all entrants was less than 20\%.[19] While cable companies have recently made inroads with digital telephone service, their progress has been largely independent of the effects of TA96.

Some critics contend that the lack of entry is due to how the law has been implemented by the Federal Communications Commission (FCC). Under TA96, entrants can lease portions of the incumbents' networks (known as unbundled network elements, or UNEs) in order to provide phone service to customers. From roughly 2001 through 2006, entrants were able to lease all of the infrastructure necessary to provide phone service to customers. Firms utilizing this platform entry approach ${ }^{1}$ could provide phone service without installing any of their own equipment. Advocates of platform entry claimed that the option was needed to make entry into residential markets economically feasible, especially given the level of customer churn in the industry.

Critics claimed that not only was platform entry unnecessary, but that it reduced the incentives for sustainable long-term competition offered by loop entry. Under loop entry $\mathrm{L}^{2}$, entrants lease only the wires that connect a customer's premises to the phone network and install their own switching equipment. Opponents of platform entry typically claimed that the availability of loop entry was sufficient to facilitate a competitive market. Further, they argued, platform entry discouraged loop entry and thus created disincentives for entrants to invest in advanced telecommunications equipment. As Michael Powell, former chairman of the F.C.C., put it, by allowing platform entry

\footnotetext{
${ }^{1}$ This means of entry is also known as UNE-Platform or UNE-P entry.

${ }^{2}$ This means of entry is also known as UNE-Loop or UNE-L entry.
} 
regulators were giving loop entrants, "the back of their hand." (U.S. F.C.C., 2003b)

Without entrant investment, it was claimed that substantial competition would not materialize 3

This paper analyzes whether platform entry limited loop entry. State-level panel data on the level of loop entry are used to answer this question. The entry data are regressed on cost, demand, and regulatory factors that are believed to influence entry. I find that platform entry may have significantly discouraged loop entry. Specifically, the point estimate of the elasticity of loop entry with respect to the price of platform entry is roughly 1.0. Based on the number and size of platform price changes over the period, a back of the envelope calculation suggests that platform price reductions reduced total loop entry in the U.S. by approximately 750,000 lines, or roughly $20 \%$ of all loop entry lines.

This study is closely related to Beard and Ford (2005) They use a pooled data set to analyze the determinants of loop and platform entry. Among their findings is that, for both types of entry, as the cost of that type of entry increases, the level of entry falls. Their estimates of the cross-price elasticity of demand suggest that loop and platform entry are not substitutes.

This paper improves upon the existing literature in at least three important dimensions. First, the data employed cover nearly the entire period during which platform entry was available. Second, state fixed effects are included in the estimations. The inclusion of these effects allows for a precise measure of the effects of changes in lease

\footnotetext{
${ }^{3}$ Another objection raised by critics of platform entry was that it reduced incentives for incumbents to invest in equipment. A number of authors have analyzed this question and their conclusions vary. Crandall (2004) and Hazlett, Havenner, and Bazelon (2003) find that the platform price is negatively related to incumbent investment, while Willig, et al (2002) and Phoenix Center (2003) do not. Researchers have also looked at the effect of platform entry on the stock returns of incumbents. See Ingraham and Sidak (2003) and Ekelund and Ford (2003). Finally, Beard, Ford, and Koutsky (2005) investigate the effect of platform entry on entrant investment, which can be viewed as a rough proxy for loop entry.

${ }^{4}$ Crandall, Ingraham, and Singer (2004) investigate whether the cost of loop entry influences the level of entry where entrants build all of the facilities (including the loop) used to provide service. They find that the loop price reduces the share of lines of which entrants build all of the facilities.
} 
prices within a given state, holding all time-invarying factors constant. Finally, lags of the explanatory variables are included to more accurately reflect the non-instantaneous effects of changes in market conditions.

The paper is organized as follows. Section 2 provides background information regarding the regulatory treatment of platform entry. The data used and estimation specification are explained in Section 3. The estimation results are described and discussed in Section 4. Section 5 concludes.

\section{Background Information}

A primary objective of TA96 is to facilitate competition in the local telecommunications market. The Act includes provisions that allow entrants to lease parts of the incumbents' networks.5 TA96 directs that the prices for these unbundled network elements (UNEs) are to be set at relatively low rates ${ }^{6}$ by state public utility commissions.

Since the passage of TA96, the FCC has grappled with the issue of what parts of the incumbents' networks should be made available as UNEs. The Act states that incumbents must make available to entrants those networks elements without which the entrant would be impaired in providing a given services. The local loop, the wires that connect a customer's premises with the broader phone network, has generally been viewed as meeting this criteria. As such, the availability of loop entry has been relatively uncontroversial.

However, the concept of platform entry has been very contentious. Two regulatory requirements are necessary for platform entry to be feasible: entrants must be able to

\footnotetext{
${ }^{5}$ Entrants into local telecommunications markets are known as Competitive Local Exchange Carriers, or CLECs, while incumbents are known as Incumbent Local Exchange Carriers, or ILECs.

${ }^{6}$ The rates are based on a TELRIC (total element long-run incremental cost) methodology. In essence, the price is to be based on the costs that a hypothetical would incur if it built the network using current technology. The Act explicitly states that the rates are not to be based on the actual historical investment by the incumbent.
} 
rebundle UNEs and all of the necessary network elements must be made declared as UNEs by the FCC.

While incumbents began allowing entrants to lease the UNEs necessary for platform entry in some states in 1999, they often charged additional fees for rebundling the network elements. In response, the FCC ruled that incumbents could not charge such fees. Litigation soon followed, culminating with a Supreme Court ruling in 2002 in Verizon vs FCC [21] that entrants can legally re-bundle UNEs at no additional charge from the incumbents.

The network element that has been at the heart of the platform entry debate is the incumbent switches, specifically those that are used to service residential and small business customers. Until 2004 most incumbent switche: 7 were available to entrants as UNEs at relatively low rates. However, in March 2004, the U.S. Court of Appeals in Washington, D.C. determined that the FCC rules did not comply with TA96.[14] In June 2004, the Bush administration announced that it would not appeal the decision by the U.S. Court of Appeals, thus ringing the death bell of platform entry at low, regulated rates.[1] The FCC then ruled in February 2005 that incumbent switches would no longer be available to entrants at the low rates as of February 2006.

\section{Empirical Specification}

Four data sets are combined to test whether platform entry discouraged loop entry. The first data set contains information regarding the number of lines leased by incumbents to entrants. Incumbent $\mathrm{s}^{8}$ are required by the FCC to report these data in their Form

\footnotetext{
${ }^{7}$ The UNE Remand Order (FCC, 1999) excluded switches in the largest 50 MSAs that were not used to serve mass market (residential \& small business) customers.

${ }^{8}$ Below I use the term incumbent to refer to Regional Bell Operating Companies (RBOCs). RBOCs are the local phone companies that were created in the 1982 breakup of AT\&T. While there are many other incumbent local phone companies, the RBOCs account for over $87 \%$ of all phone lines. 20] The analysis below is limited to RBOCs due to limitations of the data regarding the number of lines and UNE prices.
} 
477 submissions. These semi-annual data are reported beginning in January 20019 These data are the basis for the dependent variable in the analysis: the number of lines leased by entrants via loop entry.

These data are combined with the prices set in each state under the two means of entry. State public utility commissions hold proceedings in which incumbents and entrants propose prices for the hundreds of UNEs that incumbents must make available. For obvious reasons, the entrants' proposed rates are invariably lower than those proposed by incumbents. After reviewing the proposed pricing models, the commissions then choose the UNE prices. The prices typically stay in effect for two or three years, at which which point they are revisited by the commissions. Starting in April 2001, Billy Jack Gregg of the West Virginia Office of the Consumer Advocate surveyed the state public utility commissions on the prices they set for platform and loop entry. The price variables used in the analysis below are from the Gregg survey and are the monthly averages ${ }^{10}$ entrants must pay the incumbent under the two means of entry in a given state.

Information regarding federal regulation of the incumbent is also included. Under TA96, incumbents were not allowed to sell long-distance service in a state until the FCC had concluded that the market for local phone service was sufficiently open to competition 11 Thus, the incumbents had an incentive to take steps to demonstrate that entry was feasible in the market. To capture this effect, a dummy variable is included that takes a value of 1 starting when the incumbent submitted an application to sell long-distance service that was eventually approved.

\footnotetext{
${ }^{9}$ January 2001 roughly coincides with the beginning of regulated platform entry, with two exceptions. In 1998, Bell Atlantic began leasing platform lines in New York state, while Southwestern Bell began leasing platform lines in Texas in April 2000. [12]

${ }^{10}$ Each state is divided into three or four density zones, which capture the geographic concentration of customers. The lease price entrants must pay varies by density zone. The zones with higher densities have lower prices, while lower densities have higher prices. The statewide average is a weighted average based on the number of lines in each density zone.

${ }^{11}$ By December 2003, all of the companies had received permission to sell long-distance service in the states in which they operated.
} 
Finally, economic indicators are added to control for the changes in market conditions that may have influenced the level of entry. The monthly population and per capita personal income are included to control for state-specific demand shocks.

The regression data are semi-annual and cover the time period from January 2001 through July 2005. The resulting sample covers 48 states and the District of Columbia and consists of 392 observations 12 Summary information for the sample are reported in Table 1, with data regarding first differences of the variables reported in the bottom half of the table. The sample average number of lines served via loop entry in each state is roughly 75,000 , with a maximum of almost 500,000. On average, the monthly platform price is roughly $20 \%$ larger than the loop price. The first differences statistics indicate that, on average, during the sample period loop entry was increasing while loop and platform prices were falling. Figure 1 details the national averages of loop entry and the prices of loop and platform entry. The graph shows that loop entry began to level off in 2003. Also, the average gap between the price of loop and platform entry shrank from almost $\$ 6$ in 2001 to roughly $\$ 3$ in 2005 .

An important innovation in the current analysis is the inclusion of lagged values of the explanatory variables. By including lagged explanatory variables, the measured effects on loop entry are not limited to contemporaneous responses. Specifically, the values of the variables lagged six months and one year are included in the regressions below. However, the inclusion of the lags comes at a cost - the first two periods of data are lost. The resulting sample period is January 2002 through July 2005.

State fixed effects are included to control for any unobserved differences across states that do not vary over the sample period. For instance, if a given state is significantly more attractive to entry in some way that does not vary between January 2002 and July 2005, this difference will be capture by the state fixed effect. As such, the coefficient estimates will reflect the effects of changes in the explanatory variables over time within

\footnotetext{
${ }^{12}$ Data for Alaska and Hawaii are not included.
} 
a given state (and not across states) 13 Finally, a time trend variable and a squared time trend variable are included to account for non-linear patterns of entry. ${ }^{14}$

The resulting estimating equation is:

$$
\begin{aligned}
& \text { ENTRY } Y_{i, t}= \\
& \quad \beta_{0}+\sum_{k=0}^{2}\left\{\beta_{1, k} L O O P P R I C E_{i, t-k}+\beta_{2, k} \text { PLATPRICE } E_{i, t-k}\right. \\
& \left.\quad+\beta_{3, k} L D A P L_{i, t-k}+\beta_{4, k} \text { POP }_{i, t-k}+\beta_{5, k} I N C O M E_{i, t-k}\right\} \\
& \quad+\beta_{6} \text { TIMETREND + } \beta_{7} \text { TIMETRENDSQD }+\gamma_{i}+\epsilon_{i, t}
\end{aligned}
$$

where $i$ indexes the state and $t$ indexes the half-year. The index $k$ accounts for the inclusion of two lags of each of the explanatory variables that reflect cost, demand, and regulatory conditions.

Given inertia in the level of loop entry, serial correlation of the errors is a concern. Further, national shocks may create heteroskedasticity across states. These concerns are borne out in diagnostic tests. Wooldridge's test for autocorrelation indicates that the errors are serially correlated in the first order, while a likelihood ratio test indicates that heteroskedasticity is present across states. To address this concern, Prais-Winsten estimates are used that allow for first-order autocorrelation and heteroskedasticity, both within each state and across the states for a given time period. 15

Equation (1) is estimated both as a linear function and a log-linear function. The log-linear function is often used in demand analysis and has the advantage of the

\footnotetext{
${ }^{13}$ As only one incumbent serves each state, the state fixed effects also control for any time invarying factors common to a single incumbent.

${ }^{14}$ In estimations not reported below, a dummy variable was included that equaled one after the June 2004 Bush administration decision not to appeal the court ruling that struck down platform entry. The coefficient on the variable was statistically and economically insignificant and the remaining coefficients were largely unchanged.

${ }^{15}$ Ordinary least squares estimates are also employed in which Huber-White errors are clustered at the state level. While the clustered standard errors are robust to any correlation within a state, they do not allow for heteroskedasticity across panels. The results from this approach are very similar to the Prais-Winsten estimates and are reported in the Appendix.
} 
coefficients corresponding to elasticity estimates. However, as the log-linear function assumes a constant elasticity, the linear functional form is also estimated.

The coefficients of interest are $\beta_{2,0}, \beta_{2,1}$, and $\beta_{2,2}$, which correspond to the three lags of the price of platform entry. These parameters will indicate whether changes in the cost of platform entry were correlated with the changes in the level of loop entry. If these parameters are close to zero, it would suggest that availability of platform entry had a limited effect on loop entry. If instead the coefficients are significantly positive, it could indicate that entrants shifted from loop entry to platform entry in response to decreases in the cost of platform entry: ${ }^{16}$

\section{Results}

\section{$4.1 \quad$ Total Effects}

Table 2 details the total effects of each of the explanatory variables on loop entry. The effects are found by adding the coefficient estimate for each lag for each explanatory variable. For example, the total effect of the loop price on loop entry is found by adding $\beta_{1,0}, \beta_{1,1}$, and $\beta_{1,2}$. (The estimates for all of the lags are provided in Table A-1.)

Four different specifications are reported in Table 2. Columns I and II report estimates based on a linear functional form, whereas Columns III and IV are based on a log-linear specification. As such, the effects in Columns I and II should be interpreted as the effect on loop entry from a one-unit change in the explanatory variable. Conversely, the effects reported in Columns III and IV are the (constant) elasticities of loop entry with respect to the each of the explanatory variables.

The explanatory variables included also vary across the specifications. Specifica-

\footnotetext{
${ }^{16}$ An underlying assumption of this model is that the loop and platform prices are exogenous to the level of entry. As noted by Crandall, Ingraham, and Singer (2004), this assumption is reasonable given that entrants are unlikely to be able to purposely influence the prices through their entry decisions. The inclusion of state fixed effects further mitigates this concern.
} 
tions I and III only include the entry price variables, while Specifications II and IV include the regulatory and market variables. The similarity of the results in Columns I and II and Columns III and IV indicate that the estimates are robust to the included explanatory variables.

The estimates indicate that, as one would expect, the own-price effect is negative. Columns I and II indicate that a $\$ 1$ increase in the monthly loop cost is correlated with a decrease of roughly 4000 lines within one year. The result is statistically significant at a confidence level of over $99 \%$. Measured at the overall mean, a $\$ 1$ increase in loop price leads to an approximately $6 \%$ decrease in loop entry. In terms of the elasticity, the log-linear coefficients in Columns III and IV suggest that the own-price elasticity of loop entry is roughly 1.3 .

As noted above, the effect of interest is that of the platform price on loop entry. The estimates suggest that changes in platform prices influenced the level of loop entry. The coefficient estimates from the linear specification range from 1073 to 1205, with the statistical significance of the estimate in Column II only 93\%. However, the lack of statistical significance appears to be due to the coefficient of the unlagged platform price. When this coefficient is not included in the calculation of the total effect, the point estimate increases to nearly 1300 and the statistical significance rises to over $99 \%$. Conversely, the log-linear estimates in Columns III and IV are both highly statistically significant.

The economic significance of the effect of platform price on loop entry differs somewhat between the linear and the log-linear specifications. Based on the linear specification, a $\$ 1$ decrease in the platform price is correlated with a decrease of roughly 1300 lines leased by entrants via loop entry. Measured at the mean of loop entry, this translates to a less than $2 \%$ decrease. The estimated cross-price elasticities from Columns III and IV indicate that the cross-price elasticity is roughly 1.0, which indicates an arguably significant economic effect. This apparent contradiction will be 
explored further in Section 4.2

The effects from the regulatory and demand controls are somewhat surprising. The effects of the incumbent successfully applying to sell long-distance services are noteworthy. Since the application was judged by whether the local phone service market was open to competition, one would expect a positive effect on entry. The negative effect on loop entry may reflect difficulty that entrants encountered when competing with incumbents once they were allowed to sell long-distance services. The effect of income is statistically insignificant, while the effect of population of limited economic significance. These two results suggest that the state fixed effects are controlling for much of the differences in the attractiveness of entry across states.

\subsection{Elasticities}

Table 3 reports the estimated elasticities of loop entry with respect to the platform price. Columns 1 and 2 are based on the linear estimates, while Column III is based on the log-linear specification and is thus the coefficient estimates from Table 2. While Columns I and II are both based on the linear specification, they differ in how they are calculated. Column I calculates the elasticity at the sample means of the entry and price variables. Alternatively, the estimates in Column II are based on a two-step calculation. First, a state-specific elasticity is calculated for each state based on the level of loop entry and loop and platform prices in that state ${ }^{17}$ The mean of these state-specific elasticities is reported in Column II. ${ }^{18}$

Whereas the Column I estimate suggests a limited relationship between loop entry and the platform price, the estimates Columns II and III imply a stronger link. The

\footnotetext{
${ }^{17}$ The values of these variables in January 2004 were used in the calculation. This date was selected to reflect a point in the sample period when platform entry was well-established. As a robustness test, other dates were used in these calculations with little effect on the elasticity estimates.

${ }^{18}$ The cross-price elasticity estimate for West Virginia, 35.0, was judged unreliable adn excluded from the calculation of the mean.
} 
latter estimates indicate that a $10 \%$ decrease in the platform price was associated with a roughly $10 \%$ decrease in loop entry. All three figures are significantly larger than the statistically insignificant estimate of 0.1 by Beard and Ford (2002). However, as noted above, Beard and Ford use a pooled regression that reflects cross-sectional variation.

Given the divergent estimates, one is left to assess which results are more credible. The estimates in Columns II and III are arguably more plausible. Using the overall sample means to calculate the elasticity, as is done in Column I, masks the variability in the operating environments across states. The estimates in Column II incorporate this variability. Further, the estimates in Columns II and III are based on different functional forms. The similarity of these estimates provide further confidence in the estimate of roughly 1.0 .

\subsection{Estimate of Forgone Loop Entry}

Given that the price of platform entry may have been correlated with the level of loop entry, one may want to determine the total effect of changes in the platform price on loop entry during the sample period. Using the cross price elasticity estimate, a backof-the-envelope approximation of this forgone entry can be calculated. Recall that the price elasticity is calculated as

$$
\epsilon_{\text {entry,price }}=\frac{\frac{\Delta \text { Entry }}{\text { Entry }}}{\frac{\Delta \text { Price }}{\text { Price }}}
$$

The total effect on loop entry can be approximated by using the estimated elasticity, the number of platform price changes and the average amount of each change, and the average platform price and level of loop entry. Specifically, 


$$
\Delta \text { Entry }=(\text { numpricechanges }) * \epsilon_{\text {entry }, \text { price }} * \frac{\overline{\Delta \text { price }}}{\overline{\text { price }}} *(\overline{\text { entry }})
$$

During the sample period, the platform price changed 134 times, the average change was $-\$ 1.40$, the average platform price was $\$ 18.74$, and the average level of loop entry was 76,508. For simplicity, the cross price elasticity is approximated as 1.0. Based on these figures, the estimate of loop entry lines foregone for the sample period for the 48 states and the District of Columbia is approximately 750,000 lines. Given the national total of 3.8 million lines serviced by loop entry, the estimate suggests that the level of loop entry in the U.S. would have been roughly $20 \%$ higher but for the decreases in platform prices.

The estimate of forgone entry is limited by the use of the overall sample means, which abstracts away important differences across states. Further, the estimate assumes a constant cross-price elasticity, which may not be applicable. However, the magnitude of the estimate suggests that there may have been a significant negative impact on loop entry from platform entry.

\section{Conclusion}

This paper addresses whether platform entry affected loop entry in U.S. local telecommunications markets. The results suggest that platform entry may have limited loop entry. As such, some support is provided to those who believe that platform entry was a hindrance to introducing competition to local telephone markets. Further, the estimate of 750,000 forgone lines of loop may be a lower bound, as the analysis above only measures the incremental effect of platform price decreases on loop entry. Loop 
entry could have also been discouraged by the relatively low prices set for platform entry when the option was introduced. Also, there is no measurement of the potential effect of platform entry on other forms of phone service, such as those provided by cable companies and voice-over-internet-protocol providers.

Nevertheless, platform entry was widely implemented by entrants and arguably provided some customers with choices that they otherwise would not have had. Over 16 million phone lines were provided by entrants utilizing platform entry as of 2004 . For those policymakers who viewed platform entry as a relatively close substitute to loop entry, platform entry may be considered as a regulatory success.

The future of platform entry is muddled. Soon after it became clear that platform entry at regulated low prices would be eliminated, the two largest platform entry players, AT\&T and MCI, announced large asset write downs and were eventually acquired by other companies. The incumbents claim that they are open to continuing to offer platform entry and some entrants have entered into agreements to continue providing service via platform entry. However, time will tell whether platform entry at privately negotiated prices will emerge as a viable entry model. 


\section{References}

[1] Andrews, Edmund. 1996-02-09. Communications Bill Signed, and the Battles Begin Anew. New York Times.

[2] Beard, R., Ford, G., 2005. Are Unbundled and Self-Supplied Telecommunications Switching Substitutes? An Empirical Study. International Journal of the Economics of Business, 12(2), 163-181.

[3] Beard, R., Ford, G., Koutsky, T. 2005. Mandated Access and the Make-or-Buy Decision: The Case of Local Telecommunications Competition. Quarterly Review of Economics and Finance 45, 28-47.

[4] Beck, N., Katz, J. 2005. What to Do (and not to Do) with Time Series CrossSection Data. American Political Science Review 89(3), 634-647.

[5] Crandall, R. 2004. Competition and Chaos: The U.S. Telecommunications Sector Since 1996. Brookings Press: Washington, D.C.

[6] Crandall, R., Ingraham, A., Singer, H. 2004. Do Unbundling Policies Discourage CLEC Facilities-Based Investment? Topics in Economic Analysis and Policy, 4, $1-23$.

[7] Ekelund, R., Ford, G. 2003. Innovation, Investment, and Unbundling: An Empirical Update. Yale Journal on Regulation 20, 383-388.

[8] Hazlett, T., Havenner, A., Bazelon, C. 2003-09-02. Declaration of Thomas W. Hazlett, Arthur M. Havenner, and Coleman Bazelon: In the Matter of Petition for Forbearance From the Current Pricing Rules for the Unbundled Network Element Platform. U.S. F.C.C. W.C. Docket No. 03-157.

[9] Ingraham, A., Sidak, J. 2003. Mandatory Unbundling, UNE-P, and the Cost of Equity: Does TELRIC Pricing Increase Risk for Incumbent Local Exchange Carriers? Yale Journal on Regulation 20, 389-406.

[10] Phoenix Center for Advanced Legal and Economic Public Policy Studies. 2003. UNE-P Drives Bell Investment: A Synthesis Model. Policy Bulletin No. 6. http: //www . phoenix-center.org/PolicyBulletin/PolicyBulletin6Final.pdf.

[11] Squeo, A. M., Latour, A. 2004-06-10. U.S. Sides with Bells in Battle Over Local Calling. Wall Street Journal. A1.

[12] Smith, G. 2001. Putting the Horse Before the Cart: The History and Future of the UNE Platform. Z-Tel Public Policy Paper No. 1.

[13] Telecommunications Act of 1996. 1996-02-08. Public Law 104104, 110 Stat. 56.

[14] U.S. Court of Appeals for the District of Columbia Circuit. 2004-03-02. United States Telecom Association v. Federal Communications Commission. No. 00-1012. 
[15] U.S. Federal Communications Commission. 1999-11-05. Third Report and Order and Fourth Further Notice of Proposed Rulemaking: In the Matter of Implementation of the Local Competition Provisions of the Telecommunications Act of 1996. CC Docket No. 96-98.

[16] U.S. Federal Communications Commission. 2003-02-20a. Press Release: FCC Adopts New Rules for Network Unbundling Obligations of Incumbent Local Phone Carriers (Press Statement of Commissioner Kathleen Q. Abernathy).

[17] U.S. Federal Communications Commission. 2003-02-20b. Press Release: FCC Adopts New Rules for Network Unbundling Obligations of Incumbent Local Phone Carriers (Separate Statement of Chairman Michael K. Powell).

[18] U.S. Federal Communications Commission. 2005-02-04. Order on Remand: In the Matter of Unbundled Access to Network Elements. WC Docket No. 04-313.

[19] U.S. Federal Communications Commission. 2005-07. Local Telephone Competition: Status as of December 31, 2004. http://www.fcc.gov/Bureaus/Common_ Carrier/Reports/FCC-State_Link/IAD/Icom0705.pdf.

[20] U.S. Federal Communications Commission. 2005-11. Statistics of Communications Common Carriers: 2004/2005 Edition. http://hraunfoss.fcc.gov/edocs_ public/attachmatch/DOC-262086A1.pdf.

[21] U.S. Supreme Court. 2002-05-13. Verizon Communications Inc., et al. v. Federal Communications Commission. No. 00-511.

[22] Willig, R., Lehr, W., Bigelow, J., Levinson, S. 2002. Stimulating Investment and the Telecommunications Act of 1996. F.C.C. Docket 01-338. 


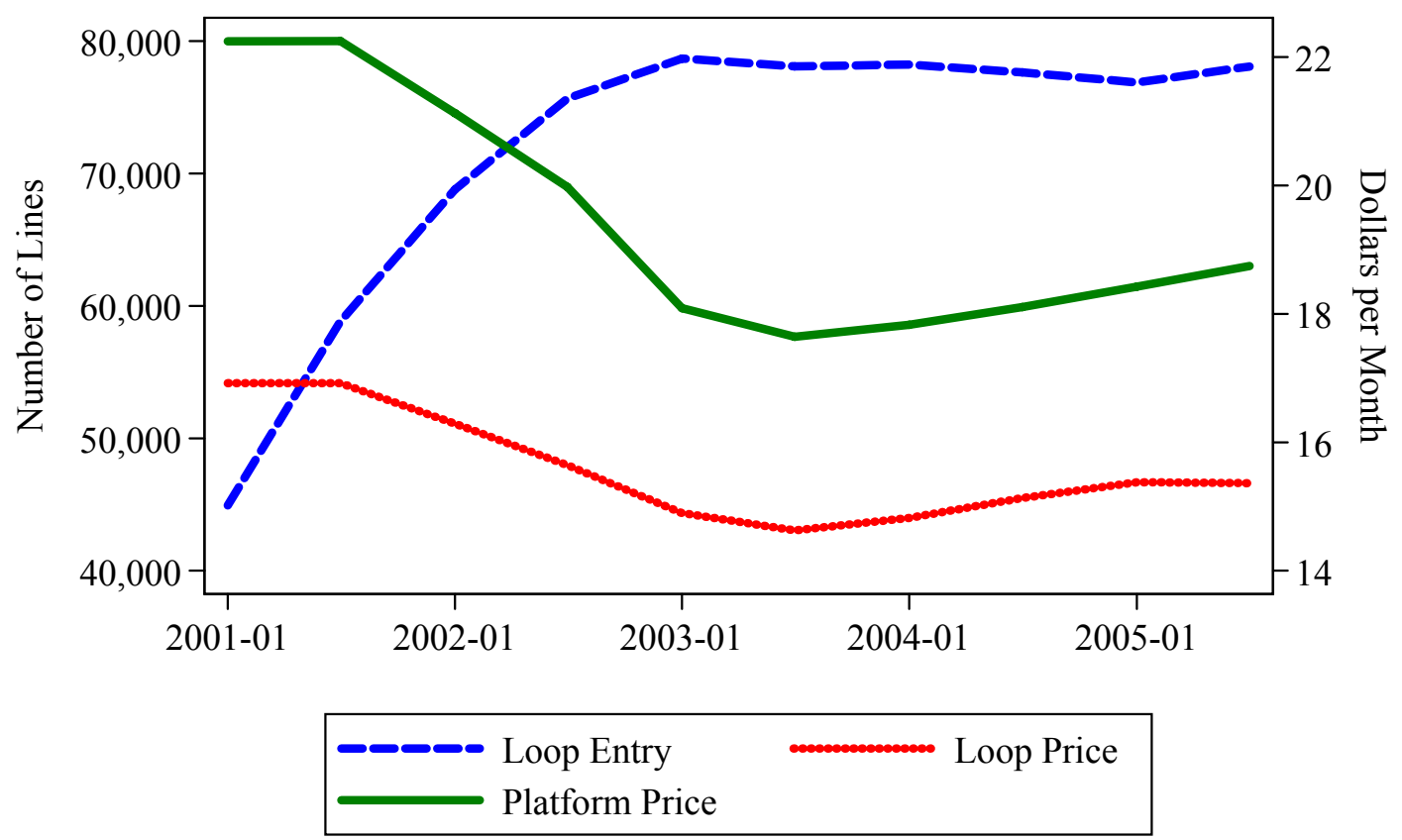

Figure 1: Loop Entry and Entry Prices (National Averages), 2001 - 2005 
Table 1: Summary Statistics

\begin{tabular}{lcccc}
\hline \hline \multicolumn{1}{c}{ Variable } & Mean & Std. Dev. & Min. & Max. \\
\hline Levels (N=392) & & & & \\
Loop Entry & & & & \\
Loop Price & 76,508 & 97,945 & 282 & 492,995 \\
Platform Price & $\$ 14.92$ & $\$ 3.88$ & $\$ 4.29$ & $\$ 27.41$ \\
Long-Distance Application & $\$ 18.74$ & $\$ 4.01$ & $\$ 5.41$ & $\$ 33.42$ \\
Per-Capita Personal Income (000) & $\$ 3.8$ & 0.4 & 0 & 1 \\
Population (000) & 5910 & $\$ 5.5$ & $\$ 14.0$ & $\$ 56.9$ \\
First Differences (N=343) & & & & \\
Loop Entry & 2578 & 9288 & $-31,840$ & 51,136 \\
Loop Price & $-\$ 0.22$ & $\$ 1.46$ & $-\$ 9.94$ & $\$ 6.83$ \\
Platform Price & $-\$ 0.55$ & $\$ 2.53$ & $-\$ 31.04$ & $\$ 7.63$ \\
Long-Distance Application & 0.12 & 0.32 & 0 & 1 \\
Per-Capita Personal Income $(000)$ & $\$ 0.53$ & $\$ 0.43$ & $-\$ 0.78$ & $\$ 2.52$ \\
Population (000) & 28.7 & 46.0 & -13 & 235 \\
\hline
\end{tabular}


Table 2: Total Effects

\begin{tabular}{lcccc}
\hline \hline & \multicolumn{4}{c}{ Dependent Variable: Loop Entry } \\
\cline { 2 - 5 } & I & II & III & IV \\
\hline Loop Price & $\left(2058^{* * *}\right.$ & $-4098^{* * *}$ & $-1.24^{* * *}$ & $-1.37^{* * *}$ \\
Platform Price & $(22.0)$ & $(78.2)$ & $(72.8)$ \\
& $1205^{* *}$ & $1073^{*}$ & $0.95^{* * *}$ & $1.03^{* * *}$ \\
Long-Distance Application & $(5.8)$ & $(3.8)$ & $(56.0)$ & $(39.5)$ \\
& & $-12,855^{* * *}$ & & 0.07 \\
Personal Income & & $(20.2)$ & & $(1.54)$ \\
& & $-1107^{*}$ & & 0.13 \\
Population & & $(3.1)$ & & $(0.02)$ \\
& & & & $-3.91^{* * *}$ \\
Specification & & $-30.4^{* * *}$ & & $(53.0)$ \\
\hline$R^{2}$ & & $(19.6)$ & & Log-Linear \\
Observations & Linear & Linear & Log-Linear & 0.35 \\
\hline \hline
\end{tabular}

${ }^{*} p<0.10,{ }^{* *} p<0.05,{ }^{* * *} p<0.01$

Chi-squared statistics are reported in parentheses.

The effects are from Prais-Winsten estimates that are based on errors that follow an AR(1) process common to each state and heteroskedasticity within states and across states in a given period.

Unless otherwise noted, the coefficients above are the sum of the coefficients of the three lags of the variable.

Time trend variables and state fixed effects omitted for brevity. 
Table 3: Elasticity of Loop Entry with Respect to Platform Price

\begin{tabular}{lccc}
\hline \hline & $\begin{array}{c}\text { Linear Measured } \\
\text { at Sample Means }\end{array}$ & $\begin{array}{c}\text { Linear Averaged } \\
\text { Across States }^{2}\end{array}$ & Log-Linear $^{3}$ \\
\hline Cross-Price Elasticity & $0.25^{*}$ & $1.13^{*}$ & $0.95^{* * *}$ \\
& $(3.31)$ & $(3.31)$ & $(56.0)$ \\
\hline \hline
\end{tabular}

${ }^{*} p<0.10,{ }^{* *} p<0.05,{ }^{* * *} p<0.01$

Chi-squared statistics in parentheses

${ }^{1}$ The elasticity is calculated at the sample means of the entry and price variables and is based on the coefficients reported in Table 2, Specification II.

${ }^{2}$ The elasticity is calculated by taking the mean of the elasticities calculated for each state (and the District of Columbia) based on the January 2004 entry and price variables. The elasticity estimate for West Virginia, 35.0, was judged unreliable and was excluded from the calculation of the mean.

${ }^{3}$ The elasticity is based on the coefficients reported in Table 2, Specification IV. 


\section{Appendix}

Table A-1: Coefficient Estimates

\begin{tabular}{|c|c|c|c|c|}
\hline & \multicolumn{4}{|c|}{ Dependent Variable: Loop Entry } \\
\hline & I & II & III & IV \\
\hline \multirow[t]{2}{*}{ Loop Price, $t$} & $-1212^{*}$ & -1037 & $-0.38 * * *$ & $-0.44^{* * *}$ \\
\hline & $(641)$ & $(639)$ & $(0.13)$ & $(0.14)$ \\
\hline \multirow[t]{2}{*}{ Loop Price, $t-1$} & $-1474^{* * *}$ & $-1558^{* * *}$ & $-0.50 * * *$ & $-0.52^{* * *}$ \\
\hline & $(506)$ & $(495)$ & $(0.10)$ & $(0.11)$ \\
\hline \multirow[t]{2}{*}{ Loop Price, $t-2$} & $-1273^{* *}$ & $-1503^{* * *}$ & $-0.36^{* * *}$ & $-0.42^{* * *}$ \\
\hline & $(505)$ & $(486)$ & $(0.12)$ & $(0.13)$ \\
\hline \multirow[t]{2}{*}{ Platform Price, $t$} & -79 & -170 & $0.22^{*}$ & $0.24^{*}$ \\
\hline & $(430)$ & $(409)$ & $(0.12)$ & $(0.13)$ \\
\hline \multirow[t]{2}{*}{ Platform Price, $t-1$} & $668^{* * *}$ & $594^{* * *}$ & $0.42^{* * *}$ & $0.42^{* * *}$ \\
\hline & $(203)$ & $(218)$ & $(0.09)$ & $(0.09)$ \\
\hline \multirow[t]{2}{*}{ Platform Price, $t$ - 2} & $616^{* * *}$ & $649^{*}$ & $0.31^{* * *}$ & $0.36^{* * *}$ \\
\hline & $(205)$ & $(216)$ & $(0.09)$ & $(0.10)$ \\
\hline \multirow[t]{2}{*}{ Long-Distance App., $t$} & & $-3956^{* *}$ & & 0.04 \\
\hline & & $(1815)$ & & $(0.03)$ \\
\hline \multirow[t]{2}{*}{ Long-Distance App., $t$-1 } & & $-5328 * * *$ & & 0.02 \\
\hline & & $(1690)$ & & $(0.03)$ \\
\hline \multirow[t]{2}{*}{ Long-Distance App., t-2 } & & $-3571^{* * *}$ & & 0.004 \\
\hline & & $(1674)$ & & $(0.027)$ \\
\hline \multirow[t]{2}{*}{ Personal Income, $t$} & & -140 & & -0.005 \\
\hline & & $(249)$ & & $(0.075)$ \\
\hline \multirow[t]{2}{*}{ Personal Income, $t-1$} & & 426 & & 0.83 \\
\hline & & $(1293)$ & & $(0.75)$ \\
\hline \multirow[t]{2}{*}{ Personal Income, $t$-2 } & & -1393 & & -0.70 \\
\hline & & $(1311)$ & & $(0.76)$ \\
\hline
\end{tabular}


Table A-1: Coefficient Estimates

\begin{tabular}{lcccc}
\hline \hline & \multicolumn{4}{c}{ Dependent Variable: Loop Entry } \\
\cline { 2 - 5 } & I & II & III & IV \\
\hline Population, $t$ & & 177 & & -8.41 \\
& & $(149)$ & & $(8.98)$ \\
Population, $t-1$ & & -249 & & $20.0^{* *}$ \\
& & $(242)$ & & $(15.8)$ \\
Population, $t$ - 2 & & 41 & & $-15.5^{* * *}$ \\
& & $(135)$ & & $(9.0)$ \\
Time Trend & $3882^{* *}$ & $8120^{* * *}$ & 2253 & $0.14^{* * *}$ \\
& $(1683)$ & $(1716)$ & $(1839)$ & $(0.02)$ \\
Time Trend Squared & $-261^{*}$ & $-400^{* * *}$ & -145 & $-0.007^{* * *}$ \\
& $(139)$ & $(134)$ & $(129)$ & $(0.002)$ \\
Estimation & Linear & Linear & Log-Linear & Log-Linear \\
\hline$R^{2}$ & 0.14 & 0.27 & 0.31 & 0.34 \\
Observations & 392 & 392 & 392 & 392 \\
\hline \hline
\end{tabular}

${ }^{*} p<0.10,{ }^{* *} p<0.05,{ }^{* * *} p<0.01$

Panel-corrected standard errors are reported in parentheses.

The Prais-Winsten estimates are based on errors that follow an AR(1) process common to each state and heteroskedasticity within states and across states in a given period.

State fixed effects omitted for brevity. 
Table A-2: Total Effects Based on OLS Estimates

\begin{tabular}{lcccc}
\hline \hline & \multicolumn{4}{c}{ Dependent Variable: Loop Entry } \\
\cline { 2 - 5 } & I & II & III & IV \\
\hline Loop Price & $-4532^{* *}$ & $-4730^{* * *}$ & $-1.34^{* *}$ & $-1.51^{* * *}$ \\
& $(6.7)$ & $(8.4)$ & $(24.6)$ & $(17.9)$ \\
Platform Price & 1034 & 1254 & $0.96^{* *}$ & $1.07^{* *}$ \\
& $(0.9)$ & $(1.6)$ & $(6.6)$ & $(6.9)$ \\
Long-Distance Application & & $-10,019^{* *}$ & & 0.14 \\
& & $(5.1)$ & & $(2.6)$ \\
Personal Income & & -1098 & & -0.11 \\
& & $(0.4)$ & & $(0.0)$ \\
Population & & & & -4.38 \\
& & $-32.1^{* * *}$ & & $(2.81)$ \\
Specification & & $(18.9)$ & & Log-Linear \\
\hline$R^{2}$ & & & & 0.38 \\
Observations & & & & 392 \\
\hline \hline
\end{tabular}

${ }^{*} p<0.10,{ }^{* *} p<0.05,{ }^{* * *} p<0.01$

The coefficients above are the sum of the coefficients of the three lags of the variable.

F-statistics are reported in parentheses and are based on Huber-White standard errors clustered by state.

Time trend variables and state fixed effects omitted for brevity. 